\title{
Ice Nuclei, Total Aerosol, and Climatology at Mauna Loa, Hawaii
}

\author{
B. G. Mendonca And R. F. Pueschel ${ }^{1}$ \\ Air Resources Laboratory, NOAA, Mauna Loa Observalory, Hilo, Hawaii 96720
}

(Manuscript received 11 August 1972, in revised form 18 October 1972)

\begin{abstract}
'The simultaneous operation of two NCAR ice nuclei counters and an integrating nephelometer at Mauna Loa Observatory over a period of 9 months shows concentration changes in the ice nuclei population that vary in direct relation to the atmospheric light scattering coefficient. Furthermore, both of these atmospheric parameters are strongly correlated with local climatology: 1) lowest values of ice nuclei concentrations and Rayleigh scattering exist when subsiding air or a strong temperature inversion prevents the advection of sub-inversion air to the monitoring site; 2 ) an increased frequency of higher ice nuclei counts and increased light scattering over a period of several hours are found when mesoscale atmospheric mixing occurs; and 3) the highest number of ice nuclei and maximum light scatter are encountered when a thermally induced air flow advects sub-inversion air to the Observatory site. These findings suggest the absence of extraterrestrial sources for light scattering and ice nucleating material, and point toward the existence of sources for hoth on Hawaii.
\end{abstract}

\section{Introduction}

Interest in atmospheric ice forming nuclei has developed since Bergeron (1935) pointed out for the first time the importance of the ice phase in precipitation processes (Mason, 1960; Mossop, 1968; Weickmann, 1970). Since the birth of Bowen's (1953) hypothesis relating rainfall singularities to major meteor showers, numerous investigations tried to document the existence of extraterrestrial sources of freezing nuclei (Bigg, 1964; Droessler and Heffernan 1965). Just as vigorous have been the measurements to define terrestrial sources and sinks of ice nuclei as well as the transport of ice nuclei over the globe (Kline, 1963; Price and Pales, 1963; Hobbs et al., 1971).

The topography and climatology of Hawaii enhances the quality of geophysical measurements performed at the Mauna Loa Observatory ( $3400 \mathrm{~m}$ MSL, $19^{\circ} 32^{\prime}$ $\mathrm{N}, 155^{\circ} 35^{\prime} \mathrm{W}$ ). The island of Hawaii, located generally upwind of the other islands of the Hawaiian chain and about $3700 \mathrm{~km}$ from the nearest continent, assures that only long-lived substances from any but local sources can affect the atmospheric parameters of interest. Contributions from local sources are minimized by the existence of only sparcely populated civilization centers along the coastal sections of the island more than $30 \mathrm{~km}$ away, and the absence of heavy industries anywhere on Hawaii. The marine trade inversion is usually found below the elevation of the Observatory and, generally, traps most of the particu-

\footnotetext{
1 Present affiliation: Atmospheric Physics and Chemistry Laboratory, NOAA, Boulder, Colo.
}

late matter emitted into the atmosphere from local terrestrial sources.

Measurements of ice nuclei at the Mauna Loa Observatory were made in 1959 (Kline, 1963) using a Weather Bureau type expansion chamber. Since then several other investigators using different instruments and techniques have followed ${ }^{2}$. The results of these measurements have varied from such extremes as the postulate of the existence of only extraterrestrial sources (Bigg, 1964; Droessler and Heffernan, 1965) to a connection between volcanic activities on Hawaii and ice nuclei storms on Mauna Loa (Hobbs et al., 1971), a favorite topic since the discovery of ice nuclei in Japanese volcanoes (Isono et al., 1959). Inherent in the varied results and the difficulty of their interpretation have been extremely low concentrations and non-uniform sampling intervals on a background of different climatological situations that determine the air masses sampled at Mauna Loa Observatory. In the summer of 1970 a collaborative program was initiated and maintained by scientists at the Mauna Loa Observatory from the National Center for Atmospheric Research, the University of Hawaii, and the National Oceanic and Atmospheric Administration with the intent of determining the background level, anomalies, peaks and fluctuations of ice nuclei in the air masses characteristic to the site (Fullerton et al., 1972). In the following discussion, data from this ice nuclei program are correlated with results from an

\footnotetext{
2 Principle investigators have been Kline (1963, 1972); Bigg (1960, 1964, 1968); Price and Pales (1963, 1964); Droessler and Heffernan (1965); Nagamoto et al. (1967); Hobbs et al. (1971); Isono et al. (1971); and Langer et al. (1971, 1972).
} 
aerosol monitoring program at the Mauna Loa Observatory and with the local climatology.

\section{Instrumentation}

Two NCAR Ice Nuclei Counters (Langer and Weickmann, 1971) were run side by side with a common air intake in a temperature-controlled room. Mixing chamber temperatures were monitored and maintained at $-21 \mathrm{C}$. Ambient air was sampled at a flow rate of 12 liters $\mathrm{min}^{-1}$. The independent measurements of similar data outputs of the two counters were used as a check on the validity of ice nuclei population measurements. An integrating nephelometer (Charlson et al., 1968) was operated from the same building to measure the total atmospheric aerosol. This instrument makes a continuous measurement of the light scattering coefficient due to aerosols of the ambient air. The wavelength definition is provided by the spectral characteristics of the light source, a xenon filled flash lamp with a peak sensitivity at about $5000 \AA$ and the S-11 spectral characteristics of the photomultiplier.

Note that these two methodologies are distinctly different and independent enough so as to exclude instrumental errors leading to wrong data interpretation with great likelihood. This was the case when Bigg (1968) in a conjectural cause-effect relationship rejected as instrumental in origin data (Kline, 1963; Price and Pales, 1963; Nagamoto el al., 1967) which are in basic agreement with our findings.

\section{Results and discussion}

Continuous data printouts of total ice nuclei integrated over 30-min intervals (Fullerton et al., 1972) for 223 days and a continuous recorder trace of total aerosol data for 180 days were analyzed from the period 14 August 1971 to 14 May 1972. The gaps in the continuous data are the result of instrument maintenance, calibration, malfunctions, and the operation of the nephelometer at other sites for short selected intervals.

An analysis of the data showed common features in trends of both ice nuclei and total aerosol monitored at the Observatory. Fig. 1 shows a typical time series of measurements. The occurrences of ice nuclei storms during afternoons are accompanied by periodic increases in the total aerosol population. The simultaneous rise in relative humidity during a prevailing upslope flow indicates the advection to the measurement site of low-level sub-inversion air.

Whenever low background counts were interrupted by brief significant increases in total aerosol or ice nuclei, these periods were labeled as "events". An event was arbitrarily defined as an order of magnitude increase in total aerosol and an increase of at least five times the background for ice nuclei.

The sampling time of aerosol was divided into periods defined by air mass type monitored at the Observatory.

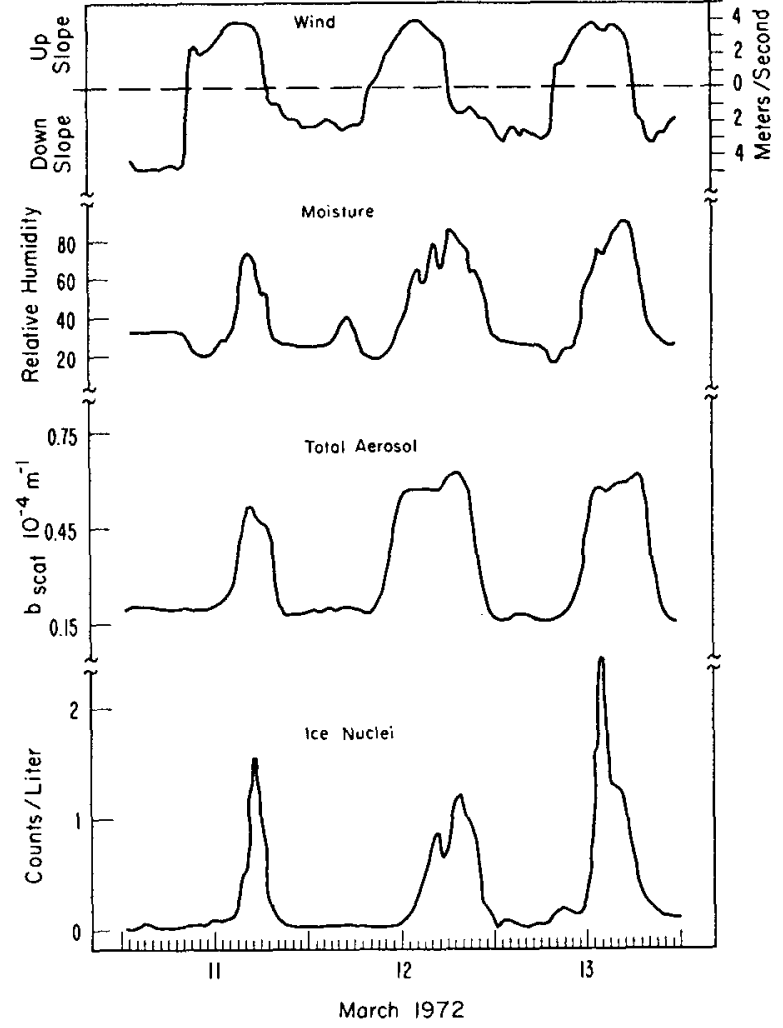

Fig. 1. Three-day sequence at Mauna Loa Observatory showing the relation between ice nuclei, total aerosol, and air mass indicators of wind velocity and moisture.

Moisture content and the direction of air flow at the Observatory were used to classify air masses sampled. Three air mass types are determined by the moisture content:

1) A stable air mass is defined during periods of relative humidity $<20 \%$. It is representative of stable air having an aged aerosol, possibly of continental origin (Simpson, 1972) with a history of transport and with no recent contact with the Pacific Ocean or the island.

2) A mixed air mass is defined during periods sampled with relative humidities variable between $20-100 \%$ for periods greater than $24 \mathrm{hr}$. This generally occurs during disturbed synoptic conditions where mixing with high humidity sub-inversion air extends to above the Mauna Loa Observatory. In these instances, the total terrestrial aerosol as well as surface moisture are mixed and entrained on a synoptic scale to great heights in the absence or breakdown of the northeast trade inversion.

3) A diurnal air mass is defined during periods when a thermally induced mountain circulation operating through a weak trade wind inversion (Mendonca, $1969 \mathrm{a}, \mathrm{b})$ transports turbid and moist sub-inversion air from below the inversion to the Observatory. Characteristic of this air mass is an afternoon transport of moisture and aerosol coincident with the upslope 


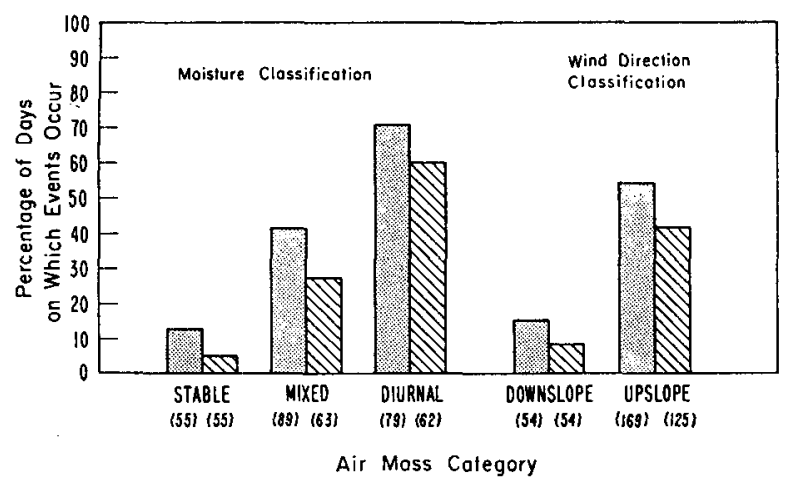

Fig. 2. Percent frequency distribution of events according to air mass category at Mauna Loa Observatory. Stippled bars are for ice nuclei; hatched bars for total aerosol. Number of sample days are in parentheses.

winds of the mountain circulation. This afternoon influx is the only interruption in an otherwise dry stable air mass as described in category 1 ).

The total number of days of observations for ice nuclei populations and total aerosol light scattering, respectively, were 55 and 55 for the stable air mass classification, 89 and 63 for the mixed air mass, and 79 and 62 for the diurnal air mass category.

In addition to the moisture classifications, two air mass types are characterized by the direction of the air flow at the Observatory:

1) When the air flow has an upslope trajectory for a portion of a day, the air mass is classified as upslope. In these instances, the thermally induced mountain circulation is dominant with a daytime upslope wind and a nightime reverse flow.

2) The remainder of the days are classified as downslope; no upslope trajectory is evident and a southerly, downslope wind direction with speeds usually in excess of $8 \mathrm{~m} \mathrm{sec}^{-1}$ prevailed for the entire period. Although directionally identical with the downslope flow in the thermal wind circulation, the cause for this flow is a large-scale pressure gradient rather than surface cooling.

There were 169 and 126 days for the diurnal air mass and 54 days each for the non-diurnal southerly flow for ice nuclei and total aerosol measurements, respectively.

In Fig. 2 are shown the percentage of days on which events occur for both ice nuclei (dotted bars) and total aerosol (hatched bars). The different air mass categories are marked below the abscissa with the number of days of observations in parentheses. The occurrence of events means an increase of ice nuclei concentration or aerosol light scattering by a factor of 5 or 10 above their background level, respectively. In both methodologies, the lowest number of occurrences of events are associated with stable air masses having an aged aerosol and no upslope island trajectory from the lower sub-inversion layer. While occasional events do occur in the upper tropospheric air mass, they are of significantly smaller magnitudes than those occurring in the other air mass types.

The greatest number of events occur when there is a transport of the lower and more turbid sub-inversion air through an island upslope trajectory to the $\mathrm{Ob}$ servatory. It is significant to note that events occur only $\sim 50 \%$ of the time during the presence of a northeast upslope trajectory, as compared to $70 \%$ of the time when there is direct evidence (e.g., a humidity increase) that sub-inversion air transport has occurred into the upper tropospheric air. The events which occur in the diurnal air mass also contain the largest quantities of both total aerosol and ice nuclei monitored, and occur during the afternoon. Although most of the events occur during periods of upslope trajectory, this climatic condition is not enough in itself to cause an event, however. But the transport of sub-inversion air either by an upslope trajectory or synoptic mixing is necessary for events which are characterized by large particulate concentrations. Whether or not this climatic condition is also sufficient for the advection of aerosols to the monitoring site apparently depends on the simultaneous existence of active sources upwind of the Observatory and the duration of a transport flow long enough for subinversion air to reach the Observatory.

Table 1 summarizes the average particulate loading resulting from both measurement methods. The background values of total aerosol measured in the stable air mass are an order of magnitude lower than the aerosol of the diurnal air mass. The corresponding ice nuclei concentrations differ by a factor of 4 . Background values of ice nuclei measured in the stable air mass at the Observatory approached the lower limits of instrument detectability and ranged from $<0.1$ to a high of $\sim 1.3$ nuclei liter ${ }^{-1}$; the high values measured in the diurnal and upslope air masses ranged from a low of $\sim 0.3$ to a high of $\sim 25$ nuclei liter ${ }^{-1}$.

These data leave little doubt that the primary source of ice nuclei and total aerosol is of island origin (Kline, 1972). It is known that there exist a large number of sources of total aerosol on the island of

TABLs: 1. Average particulate loading at Mauna Loa observatory.

\begin{tabular}{ccc}
\hline Air mass category & $\begin{array}{c}\text { Ice nuclei } \\
(\text { nuclei } \\
\left.\text { liter }^{-1}\right)\end{array}$ & $\begin{array}{c}\text { Total aerosol* } \\
\left(\mu \mathrm{g} \mathrm{m}^{-3}\right)\end{array}$ \\
\hline Stable & 0.5 & 0.5 \\
Mixed & 0.8 & 3.8 \\
Diurnal & 2.0 & 7.0 \\
Downslope & 0.4 & 0.7 \\
Upslope & 1.3 & 5.3 \\
\hline
\end{tabular}

* The conversion from light scattering coefficient to aerosol mass is based on a relationship found by Charlson et al. (1968). 
Hawaii (Pueschel and Mendonca, 1972). Preliminary investigations show that sugar cane fires on the island are the most prolific sources of ice nuclei. Schnell and Vali (1972) have shown a correlation of ice nuclei counts with decomposing vegetation which is available in the areas of lush tropical vegetation and the soils of harvested sugar cane fields on the island. While the contribution of volcanic activity, which was present on the island during most of the study, to the total aerosol is definitely significant, a relationship between active volcanic fountaining at Kilauea and the ice nuclei population at Mauna Loa Observatory at $45 \mathrm{~km}$ distance could not be established. Preliminary sampling of volcanic fumes at Kilauea show little contribution to the ice nuclei inventory (Langer et al., 1972) as opposed to the results of Isono et al. (1959) in Japan.

\section{Summary and conclusions}

A data evaluation procedure correlating ice nuclei measurements with total aerosol and the local climatology conclusively demonstrated the following points:

1. Measurement of ice nuclei and total atmospheric aerosol at the Mauna Loa Observatory show similar trends which are determined by prevailing climatological conditions.

2. Typical background concentrations of $5.0 \times 10^{-1}$ ice nuclei liter-1 and $6.0 \times 10^{-4} \mu \mathrm{g} \operatorname{liter}^{-1}$ of total atmospheric aerosol are measured in the upper tropospheric air mass of long Pacific transport.

3 . Higher values of at least an order of magnitude in total atmospheric aerosol and a factor of 4 for ice nuclei are frequently observed which can be traced to an island origin and are found during the transport of subinversion air of the northeast trades to the $3400 \mathrm{ml}$ level $(680 \mathrm{mb})$.

4. Anomalous peaks occasionally occur in the background values of the stable air mass but are lower in magnitudes and less frequent in occurrence than the other peaks associated with an island trajectory and the sub-inversion layer.

While there are occasional events of ice nuclei occurrences on Mauna Loa in the absence of light scattering aerosol clouds, a positive correlation between these two parameters exists in the great majority of over 200 cases observed between August 1971 and May 1972. Taking into account the local climatology, we could demonstrate that sources on Hawaii produce both aerosol and ice nuclei at a higher frequency of occurrence and a higher particle concentration than extraterrestrial or trans-Pacific sources. No correlation has been found between the advection of ice nuclei to Mauna Loa and Local volcanic activities, indicating that the fumes emitted by Hawaiian volcanoes do not contain freezing nuclei to a significant extent.
Acknowledgments. The authors are indebted to the following individuals: Dr. R. T. Hansen of the NCAR Solar Observatory on Mauna Loa who initiated the ice nuclei program; C. J. Garcia of the same institution who was primarily responsible for its operation; and Dr. G. Langer and J. Weickmann of NCAR's Laboratory for Atmospheric Sciences who calibrated both NCAR Nucleus Counters. The instruments were made available by Profs. C. M. Fullerton of the University of Hawaii and P. V. Hobbs of the University of Washington.

\section{REFERENCES}

Bergeron, T., 1935: On the physics of clouds and precipitation. Proc. 5th Assembly UGGI, Vol. 2, Lisbon, p. 156.

Bigg, E. K., 1960: Summary of measurements of ice nucleus concentrations. Bull. Obs. Puy de Dome, No. 3, 89-97.

- -, 1964: Geographical differences in concentrations of ice nuclei. Mon. Wea. Rev., 92, 355-356.

- - and G. T. Miles, 1964: The results of large-scale measurements of natural ice nuclei. $J$. Atmos. Sci., 21, 396-403.

-., 1968: Ice nucleus concentrations in Hawaii. J. Appl. Meleor., 7, 951-952.

Bowen, E. G., 1953: The influence of meteoritic dust on rainfall. A ustralian J. Pliys., 6, 490-497.

Charlson, R. J., N. C. Ahlquist and H. Horvath, 1968: On the generality of correlation of atmospheric aerosol mass concentration and light scatter. Amos. Environ., 2, 455-464.

Droessler, E. G., and K. J. Heffernan, 1965: Ice nucleus measurements in Hawaii. J. A ppl. Meteor., 4, 442-445.

Fullerton, C. M., G. Langer, C. J. Garcia, R. T. Hansen, R. Cook, E. Yasukawa, M. Meir, R. Uchida, J. Weickmann, B. G. Mendonca and R. F. Pueschel, 1972: Data summary and review of ice nuclei monitoring program at Mauna Loa Observatory, Aug. 71 to May 72. NCAR Tech. Rept. (in preparation).

Hobbs, P. V., C. M. Fullerton and G. C. Bluhm, 1971: Ice nucleus storms in Hawaii. Nature, 220, 90-91.

—_, G. C. Bluhm and T. Ohtake, 1971: Transport of ice nuclei over the north Pacific Ocean. Tellus, 23, 238-239.

Isono, K., M. Komabayashi and A. Ono, 1959: Volcanoes as a source of atmospheric ice nuclei. Nature, 183, 317-318.

- , M. Komabayashi, 'T. Takeda, T. Tanaka, K. Iwai and M. Fujiwara, 1971: Concentrations and nature of ice nuclei in the rim of the north Pacific Ocean. Tellus, 23, 40-59.

Kline, D. B., 1963: Evidence of geographical differences in ice nuclei concentrations. Mon. Wea. Rev., 89, 263-272.

-.-, 1972: Measurements of the ice nucleus and associated chloride particles concentrations at Mauna Loa Observatory. J. Appl. Meteor., 11, 684-687.

Langer, G., and J. O. Weickmann, 1971: Detailed evaluation of the NCAR nucleus counter-initial report. Preprints, Intern. Conf. Weather Modification, Canberra, Australia, Amer. Meteor. Soc.

- - , R. F. Pueschel, B. G. Mendonca and C. J. Garcia, 1972: Terrestrial sources of freezing nuclei in Hawaii (in preparation).

Mason, B. J., 1960: The nucleation and growth of ice crystals. Geophys. Monogr., No. 5, Amer. Geophys. Union, 226-232.

Mendonca, B. G., 1969a: The trade wind inversion at the slopes of Mauna Loa, Hawaii. J. Appl. Meteor., 8, 213-219.

- - 1969b: Local wind circulation on the slopes of Mauna Loa. J. Appl. Meteor., 8, 533-541.

Mossop, S. C., 1968: Comparisons between concentration of ice crystals in cloud and the concentration of ice nuclei. $J$. Rech. Atmos., 3, 119-124.

Nagamoto, C. T., J. Rosinski and G. Langer, 1967: Ice nuclei concentrations in Hawaii during the period 7 January to 10 March. J. Appl. Meteor., 6, 1123-1125. 
Price, S., and J. C. Pales, 1963: Local volcanic activity and ice nuclei concentrations on Hawaii. Arch. Meleor. Geophys. Bioklim., 13, 398-401.

— and - 1964: Ice nucleus counts and variations at $3.4 \mathrm{~km}$ and near sea level in Hawaii. Mon. Wea. Rev., 92, 207-221.

Pueschel, R. F., and B. G. Mendonca, 1972: Sources of atmospheric particulate matter on Hawaii. Tellus, 24, 139-149.
Schnell, R. C., and G. Vali, 1972: Atmospheric ice nuclei from decomposing vegetation. Nature, 236, 163-165.

Simpson, H. J., 1972: Aerosol cations at Mauna Loa observatory. J. Geophys. Res., 77, 5266-5277.

Weickmann, H., 1970: Die Entwicklung unserer Anschauungen uber Atmospharische Eisbildung seit Wegener. Z. Polarforsch., 7, 57-72. 